\title{
Correction to: Associations of serum 25- hydroxyvitamin $D$ with metabolic syndrome and its components in elderly men and women: the Korean Urban Rural Elderly cohort study
}

Su Jin Lee ${ }^{1,2+}$, Eun Young Lee ${ }^{3+}$, Jung Hyun Lee ${ }^{2}$, Jong Eun Kim ${ }^{4}$, Kwang Joon Kim6, Yumie Rhee ${ }^{1}$, Hyeon Chang Kim², Yoosik Youm ${ }^{5}$ and Chang Oh. Kim ${ }^{6 *}$

Correction to: BMC Geriatr (2019) 19:102 https://doi.org/10.1186/s12877-019-1118-y

Following the publication of this article [1], the authors reported an error in one of the author's names. In this Correction the incorrect and correct author name are shown. The original publication of this article has been corrected.

Originally the author name was published as:

- Kwang Jun Kim

The correct author name is:

- Kwang Joon Kim

\section{Author details}

'Department of Internal Medicine, Severance Hospital, Endocrine Research Institute, Yonsei University College of Medicine, Seoul, South Korea.

${ }^{2}$ Department of Preventive Medicine, Yonsei University College of Medicine, 50-1 Yonsei-ro, Seodaemun-gu, Seoul, South Korea. ${ }^{3}$ Division of

Endocrinology and Metabolism, Department of Internal Medicine, Seoul St. Mary's Hospital, College of Medicine, The Catholic University of Korea, Seoul, South Korea. ${ }^{4}$ Graduate School of Public Health Yonsei University, Seoul, South Korea. ${ }^{5}$ Department of Sociology, Yonsei University, 50 Yonsei-ro, Seodaemun-gu, Seoul, South Korea. ${ }^{6}$ Division of Geriatrics, Department of Internal Medicine, Yonsei University College of Medicine, 50-1 Yonsei-ro, Seodaemun-gu, Seoul 03772, Republic of Korea.
Received: 29 April 2019 Accepted: 29 April 2019

Published online: 08 May 2019

\section{Reference}

1. Lee SJ, et al. Associations of serum 25-hydroxyvitamin D with metabolic syndrome and its components in elderly men and women: the Korean Urban Rural Elderly cohort study. BMC Geriatr. 2019;19:102 https://doi.org/ 10.1186/s12877-019-1118-y.

\footnotetext{
* Correspondence: COKIM@yuhs.ac

${ }^{\dagger}$ Su Jin Lee and Eun Young Lee contributed equally to this work.

${ }^{6}$ Division of Geriatrics, Department of Internal Medicine, Yonsei University College of Medicine, 50-1 Yonsei-ro, Seodaemun-gu, Seoul 03772, Republic of Korea

Full list of author information is available at the end of the article
}

(c) The Author(s). 2019 Open Access This article is distributed under the terms of the Creative Commons Attribution 4.0 International License (http://creativecommons.org/licenses/by/4.0/), which permits unrestricted use, distribution, and reproduction in any medium, provided you give appropriate credit to the original author(s) and the source, provide a link to the Creative Commons license, and indicate if changes were made. The Creative Commons Public Domain Dedication waiver (http://creativecommons.org/publicdomain/zero/1.0/) applies to the data made available in this article, unless otherwise stated. 